\title{
Municipalização e inovação gerencial. Um balanço da década de 1990
}

\author{
Municipalization and management innovation.
} An inventory of the 1990s

Abstract This study analyzes the management innovations that occurred during the health policy decentralization process in Brazil, based on research focusing on health policy municipalization and innovations in the State of Rio de Janeiro. After an exhaustive analysis of the Unified Health System (SUS) in Rio de Janeiro, five municipalities from the State were selected which presented good performance in health system management: Angra dos Reis, Duque de Caxias, Niterói, Resende, and Volta Redonda. Based on interviews with health system managers, the first part of the article analyzes how the decision-making process takes place in the five Municipal Health Departments. The second part of the study draws on the results of the implementation of health services as perceived by health professionals providing care to users at the municipal level. We felt that exploring policy innovations incorporated into the municipal health system and the issue of provision of health care to patients would provide a relevant basis of comparison for establishing parameters or indicators allowing for future evaluation of health policy at the local level.

Key words Management innovation, Implementation, Decentralization
Resumo O presente trabalho tem por objetivo analisar as inovações gerenciais que se produziram no setor da saúde no processo de descentralização da política de saúde. O trabalho se valeu dos resultados da pesquisa sobre municipalização e inovações na implementação da política de saúde no Estado do Rio de Janeiro. Após exaustivo mapeamento da situação do Sistema Único de Saúde (SUS) no Estado do Rio de Janeiro, foram selecionados cinco municipios do Estado que apresentavam um bom desempenho no que se refere ao modelo de gestão: Angra dos Reis, Duque de Caxias, Niterói, Resende e Volta Redonda. O artigo, na sua primeira parte, indaga através das entrevistas realizadas com os gestores municipais do sistema de saúde a maneira como acontece o processo decisório nas secretarias municipais de Saúde dos municípios estudados. A segunda parte se valeu daqueles resultados relacionados à operacionalização dos serviços de saúde municipais, através da percepção dos profissionais de saúde na atividade direta de assistência aos usuários. De fato, explorar as inovações politicas incorporadas ao sistema municipal de saúde, junto com a problemática do exercício da assistência direta aos pacientes nos pareceu um bom contraponto para estabelecer parâmetros ou indicadores que permitam, no futuro, avaliar as políticas de saúde no âmbito local. Palavras-chave Inovação gerencial, Operacionalização, Descentralização 


\section{Introdução}

O artigo que se segue é resultado de uma pesquisa sobre municipalização e inovações na implementação da política de saúde. Com esta finalidade e após exaustivo mapeamento da situação do Sistema Único de Saúde (SUS) no Estado do Rio de Janeiro, foram selecionados cinco municípios do estado que apresentavam um bom desempenho no SUS no que se refere ao modelo de gestão: Angra dos Reis, Duque de Caxias, Niterói, Resende e Volta Redonda. Os critérios utilizados para a seleção dos municípios foram os seguintes: 1) o sistema de premiação instituído pela Fundação Ford para aqueles municípios que desenvolveram políticas de excelência no país em gestão administrativa, gestão de recursos humanos, recursos financeiros aplicados a políticas direcionadas para população de baixa renda, controle social na aplicação de recursos e outras experiências inovadoras; 2) a partir desse levantamento foram realizadas entrevistas com os secretários municipais de saúde de aproximadamente dez desses municípios premiados no Estado, com a finalidade de obter informação sobre o desenvolvimento da política de saúde e a implantação de experiências inovadoras; e 3 ) levantamento de documentos e dados sobre o andamento da descentralização nos municípios do estado.

\section{A descentralização no fim dos anos 80}

O crescimento do movimento municipalista/descentralizador no país adquire consenso e chega a seu ápice na década de 1980, onde desempenha um papel de relevância no processo de mudança constitucional. A Constituição de 1988 reconsidera o papel de estados e municípios perante a União, redefinindo o pacto federativo que passa a ter como eixo a descentralização das definições políticas, recursos financeiros e fundamentalmente serviços nas instâncias descentralizadas em Estados e municípios.

Uma vez sancionada a Constituição, o processo de descentralização passa a se desenvolver efetivamente, saindo da esfera virtual do discurso político e se colocando no plano da disputa de interesses dos atores no âmbito local, estadual e federal e em torno de políticas públicas concretas: saúde, educação, saneamento e outros.

Nesse sentido, a descentralização da política de saúde teve que lidar com o fato da desigualdade existente entre os municípios da fe- deração, o que levou o processo de regulamentação do setor, através das Normas Operacionais Básicas, a ter difícil acolhida por parte do complexo panorama municipal. Esse processo colocou, sempre em jogo e como pano de fundo, as contrapartidas financeiras do SUS, como um elemento de forte resistência e pressão para que a maioria dos municípios não se habilitasse a efetivar o processo de municipalização da saúde.

Ao observar a modalidade de relacionamento entre a União e os Estados pode-se constatar que historicamente esses últimos têm tido um papel importante na definição das políticas da Federação. Esse fato acontece através de mecanismos diversos.

De uma parte, as disparidades socioeconômicas entre estados e regiões são enormes; os indicadores sociais, se comparada a região $\mathrm{Su}$ deste com a Nordeste, mostram que a renda por habitante, a esperança de vida, a educação, a alimentação, o acesso aos serviços de saúde, as condições de vida e de trabalho da população correspondem aos indicadores encontrados em países desenvolvidos e infradesenvolvidos.

De outra parte, essas diferenças regionais geraram um sistema de contrapesos políticos observável através da composição das representações estaduais no Congresso Nacional. As regiões e estados menos desenvolvidos possuem maior representação proporcional que as regiões Sul e Sudeste, o que força o Governo Federal e o Congresso a incorporarem na agenda os problemas advindos das desigualdades regionais. Também e sob a perspectiva do sistema tributário, a Constituição de 1988, preocupou-se em contrabalançar as desigualdades regionais em termos da redistribuição do gasto vis-à-vis o montante das receitas tributárias.

As modalidades políticas e econômicas de contrabalançar as diferenças entre estados mais pobres versus mais ricos têm conduzido a um sistema de protecionismo político e econômico da federação vis-à-vis os estados. Ao tempo que o desenvolvimento econômico, social e humano dessas regiões é visto pelas direções políticas desses estados mais carentes - veja-se a seca no Nordeste - como sendo obrigatoriamente subsidiado pela União, favorecendo, desse modo, formas arcaicas de patrimonialismo e clientelismo político das elites locais que passam a instituir mecanismos de apoio ao executivo em troca de cargos de governo, moratória das dívidas estaduais com a Federação, não-pagamento dos compromissos etc. Situações que se encon- 
tram, de outra parte, favorecidas pelo peso superdimensionado das bancadas estaduais dos estados mais pobres que atuam como grupos de pressão, impedindo o quórum necessário em assuntos de interesse do país como um todo ou simplesmente, votando contra os mesmos.

Nesse contexto as inovações no relacionamento entre União e estados, num processo de descentralização que incorpore acordos cooperativos (Lobo, 1988) entre a União, estados e municípios, se tornam extremamente difíceis e complicadas. A análise acima objetiva evidenciar as dificuldades, na instância estadual, na implementação da descentralização. De fato, a descentralização da política de saúde tem permanecido atrelada às definições dos governos estaduais face aos acordos e desavenças - troca de favores e votos - com o Governo Federal. Assim, é notável o atraso desta instância na implementação da política de saúde, como veremos adiante.

De qualquer maneira, a última metade da década é marcada pelos avanços inéditos que a Constituição traz nos aspectos relativos à descentralização das políticas públicas com a conseqüente reordenação do sistema em torno dos princípios do Sistema Único de Saúde e da descentralização das atividades do nível federal para os estados e municípios.

\section{A recentralização na década de 1990. $O$ caso da política de saúde}

Trata-se de um momento caracterizado pela atuação da União que, de uma parte, captura recursos dos estados e municípios e, de outra, impõe modalidades de exercício da política como condicionante para o repasse dos mesmos. No caso da política municipal esta se vê coagida a abandonar princípios sustentados pela constituição de promoção política de caráter universal em favor de ações focalizadas para setores da população.

O executivo atua de maneira errática e diferenciada entre estados e municípios. Em relação aos estados, a União assume as dívidas públicas contraídas por eles com os bancos privados e, em troca, exige dos Estados a privatização das empresas públicas e a adoção de um programa de ajuste fiscal, reduzindo a folha de pagamento via demissões de funcionários. De outra, negocia com os governadores o apoio das bancadas estaduais para a aprovação da reforma administrativa e da previdência de caráter restritivo e de corte de benefícios sociais. E finalmente exige dos estados o pagamento imediato das suas dívidas com a União. Configurase assim a retomada, por parte do governo federal, dos velhos padrões do patrimonialismo político que tinham marcado a atuação do executivo pelo autoritarismo, clientelismo, e centralização burocrática. $\mathrm{O}$ exercício de tal política acaba gerando o recrudescimento da oposição ao executivo por parte dos governadores que se negaram a pagar as dívidas ao tempo que as suas representações no Congresso não aprovam as propostas de reformas do executivo.

De uma parte, é de nosso interesse tratar os avanços que têm se produzido na municipalização da política pública em geral. Nesse sentido, os indicadores para o tratamento dessa questão são dados pelo processo de construção de um pacto federativo que atribua novas modalidades de relacionamento entre federação, estados e municípios. Mas, o que se observa é uma política errática que não constrói pactos cooperativos entre instâncias de governo. Houve algumas tentativas de saneamento fiscal, a partir de 1994, sob o governo de Fernando Henrique Cardoso, como resposta ao crescimento desmedido das dívidas públicas dos estados. Kugelmas \& Sola (2000) consideram que a dívida chegou em torno dos 100 bilhões, valor mais alto do que a dívida externa de todos os países emergentes. O crescimento da arrecadação dos fundos sociais PIS, CONFINS e outros permitiu maior disponibilidade de recursos nos Cofres da União já que o resultado da arrecadação sobre esses fundos pode ser definido exclusivamente pela esfera central e se manter nos cofres federais sem obrigatoriedade de repasse a estados e municípios.

Mas, fundamentalmente, observa-se que as relações políticas entre federação, estados e municípios se tornaram críticas devido às conjunturas econômico-financeiras - escassez de recursos e aumentos das dívidas públicas nas três instâncias de governo - marcadas por comportamentos políticos erráticos que passaram do plano das negociações às crises e rupturas políticas entre a União e os estados. $\mathrm{Ku}$ gelmas \& Sola (2000) fazem referência ao primeiro período do governo FHC como um período marcado pelas tentativas de gerar um novo padrão nas relações entre a União e os Estados, com o intuito do reenquadramento destes últimos às decisões tomadas pelo poder central em vista a uma solução para os desequilíbrios fiscais. De fato, os intentos de recentralização, nesse período, configuraram, mais do que a 
construção de tendências cooperativas, uma guerra fiscal entre federação, estados e municípios (Gerschman, 2000).

De outra, a municipalização da política de saúde e os avanços que nela se produziram trazem para o centro da reflexão a especificidade do processo de descentralização num campo específico da política; tanto no que se refere ao alcance e à profundidade desta quanto à definição do papel do município na produção de inovações na gestão local. Partimos, neste trabalho, das conclusões alcançadas em artigo anterior (Gerschman, 2000), no qual afirmávamos que as inovações na gestão local relacionadas à incorporação, especificamente, de programas tais como Saúde da Família e outros são associados à adequação do município às exigências colocadas pelas Normas Operacionais Básicas que regulam a política. Os municípios conseguem dessa maneira aceder a recursos federais que passam a ser usufruídos no nível local.

No que se refere ao comportamento do financiamento do setor nos finais dos anos 90 (Gerschman, 2000), os gastos federais em saúde diminuíram significativamente se comparados aos dos anos anteriores. Mas, de outra parte, houve uma mudança significativa nas transferências diretas de recursos da esfera federal para a municipal. Em 1992, 72,3\% dos gastos em saúde correspondiam à União; 14,9\%, aos estados e 12,8\%, aos municípios; já em 1998, do total dos recursos federais do SUS, $55,4 \%$ foram gastos pela federação, $0,4 \%$ pelos estados e $44,2 \%$ pelos municípios. Essa alteração substancial no repasse dos recursos, se comparada com os primeiros anos da década de 1990, se explica pelos avanços que se produziram na regulação do processo de implementação do SUS através de Normas Operacionais Básicas. Elas definiram a Gestão Semiplena do sistema municipal de saúde, no ano de 1993 e a posterior Gestão Plena de Atenção Básica/Gestão Plena de Sistema, no ano de 1996.

Será objeto deste trabalho a maneira como os gestores municipais constroem e inserem o policy-making nos padrões de modalidades políticas locais, seja recriando-os e/ou produzindo mudanças na política local. Junto a atuação dos gestores locais serão também analisados o perfil dos médicos que atuam nos serviços destes municípios, a satisfação destes com o trabalho nas suas várias modalidades, a qualidade da infra-estrutura dos serviços municipais e as relações destes profissionais com as secretarias municipais respectivas e com o SUS como um todo.

\section{Inovação gerencial nas secretarias municipais}

O estudo do policy-making do setor resultou da análise de questões aplicadas, via questionário, aos gestores do primeiro escalão das secretarias municipais de saúde acima relacionadas, e sobre cinco eixos temáticos:

- as relações entre instâncias governamentais;

- as inovações gerenciais;

- o papel do Conselho Municipal de Saúde;

- a implantação e avaliação de programas;

- as relações da Secretaria Municipal de Saúde com o SUS

Consideramos que a idéia-força de inovação gerencial, associada ao processo de municipalização da política de saúde em curso, será contemplada pela combinação de um conjunto de variáveis dentre as quais à intervenção de atores comunitários dar-se-a um peso maior na avaliação da atuação político-gerencial das secretarias municipais de Saúde sobre as quais se focaliza o presente estudo.

As variáveis consideradas na avaliação do policy-making do setor são: o papel das burocracias técnico-políticas inseridas nas instituições municipais na definição e avaliação de programas prioritários; as relações intersetorias e entre instâncias de governo - federal, municipal e estadual-; a incorporação de novos atores comunitários e incorporações introduzidas por exigência de aplicação da própria política tais como, os conselheiros municipais e gestores setoriais participantes em fóruns específicos, como as comissões intergestoras constituídas pelo conjunto dos secretários estaduais e municipais da política de saúde e de gestores representantes do setor de educação, trabalho, assistência social que deliberam sobre a implementação do setor saúde. Trata-se de um conjunto de novos atores que interagem no interior das secretarias, pressionando as técnicoburocracias locais para a readequação e/ou reformulação das culturas institucionais de maneira a preservar ou construir o poder institucional local para operacionalizar o SUS. Finalmente, será considerado um conjunto de variáveis indicativas da inserção da SMS ao SUS.

A organização técnico-gerencial dos serviços de saúde, tanto ambulatoriais ou hospitalares, como dos programas, constitui um espaço privilegiado para a observação do policy-making no setor. As mudanças operadas nas relações institucionais entre instâncias governamentais próprias do setor e/ou áreas afins de 
política social, a aplicação de recursos financeiros, a implementação de novos serviços, investimentos em infra-estrutura e recursos humanos, a própria gestão dos recursos humanos existentes, a preocupação com o sistema de informações constituem esferas de governo sobre as quais indagamos. Nossa expectativa é que os resultados obtidos possibilitem reconstituir as inter-relações entre grupos de interesse, representantes das comunidades, burocracia, partidos políticos e especialistas que juntos desenham a política local.

\section{Os gestores municipais de saúde no processo decisório}

Em primeiro lugar, gostaríamos de fazer algumas referências a quem são esses gestores que compõem o primeiro escalão nos cinco municípios analisados, já que, junto aos secretários municipais, definem a política de saúde no município. Trata-se na sua maioria de mulheres com mais de 36 anos de idade, instrução superior completa, de profissão médica, na faixa salarial acima de 20 salários mínimos e ocupando cargos de diretoria de área ou de gerência de serviços ou programas.

Indagamos desses gestores como acontece o processo decisório nas Secretarias Municipais de Saúde dos municípios estudados, onde estão centralizados a implementação orçamentária, as políticas e as ações, os recursos materiais e a política gerencial. A prefeitura define o orçamento para a saúde, a folha de pagamento, os investimentos e os recursos humanos, mas não interfere na gestão dos gastos. De modo geral, pode-se observar que importantes mudanças têm se produzido na operacionalização do sistema de saúde municipal a partir da regulação do setor pela via de Normas Operacionais Básicas, editadas pelo Ministério de Saúde. Essas normas são produtos da existência das Comissões Intergestores, ou seja, de esferas técnico-políticas compostas pelo conjunto dos secretários municipais e estaduais de Saúde de todo o país, o Conselho Nacional de Saúde e das autoridades do Ministério da Saúde e dos ministérios da área social. Esse modelo requer uma complexa engenharia político-institucional resultante de um processo de negociação capaz de gerar a "concertação" entre a tecnoburocracia estatal, a burocracia política ou direção ministerial, os secretários municipais e estaduais e os representantes das organizações sociais e de usuários, profissionais de saúde e rede filantrópica conveniada.

Um dos aspectos indicativos do desenvolvimento do processo decisório local na descentralização da política de saúde refere-se à articulação entre instâncias de governo e fluidez das relações entre as mesmas. A cooperação municipal acontece para $68,8 \%$ dos gestores, sendo que para $43,8 \%$ dos mesmos esses espaços institucionais de articulação existem entre as próprias secretarias municipais. Observa-se que a maioria dos gestores $(93,8 \%)$ tem uma agenda de contatos com as secretarias estaduais. No entanto, grande parte deles $(43,8 \%)$ relaciona-se sem periodicidade e em função de programas específicos. Os repasses de recursos financeiros que as SES fazem para as SMS, através de gestores, estão assim distribuídos: 37,5\% para medicamentos e $31,3 \%$ para programas conjuntos. A existência de parcerias entre as SMS e as SES foi relatada por $62,5 \%$ dos gestores, enquanto $37,5 \%$ consideram que não existem relações desse nível. Observa-se, no caso, um processo pouco cooperativo entre município e Estado, situação quase sempre relacionada às diferenças político-partidárias existentes entre governos estaduais e municipais. Diferentemente, na esfera federal, no que diz respeito ao Ministério da Saúde, a totalidade dos gestores relata a existência de relações, sendo que para $31,3 \%$ essa freqüência é mensal e para $12,6 \%$, semanal e quinzenal; e para apenas $12 \%$ é irregular. No que se refere à integração do município ao SUS: dos municípios selecionados somente um deles não participa da Comissão Bipartite; dos quatro restantes, 50\% participam de todas as reuniões, $6,3 \%$ participam das reuniões ordinárias eventualmente e 37,5\% não sabem a freqüência de participação em reuniões.

Quanto à Programação Pactuada Integrada/PIS, indicadora do grau de integração na definição da implementação do SUS no estado, observa-se que, a despeito de $68,8 \%$ dos gestores dizerem que ela existe quando se pede que descrevam como funciona esta atividade, temse o seguinte resultado: $37,5 \%$ não sabem; $18,8 \%$ respondem que ainda não funciona; $6,3 \%$ dizem que alguns serviços de alta complexidade são feitos em outros municípios e apenas $6,3 \%$ informam que a PIS acontece através de uma reunião regular dos gestores da Região Metropolitana II.

A incorporação do planejamento como metodologia de gestão municipal é considerada 
fundamental para 75\% dos gestores. Mas quando são interpelados sobre a posição institucional atribuída ao planejamento, 50\% respondem que este se localiza no primeiro escalão da Secretaria enquanto que $45 \%$ afirmam que não têm uma posição definida no interior das mesmas. O processo de planejamento é organizado para $43,8 \%$ dos entrevistados, através de reuniões periódicas que vão do primeiro escalão da SMS até o nível de quem executa as ações de saúde; $31,3 \%$ dos gestores respondem que a gestão participativa dos usuários com as Conferências Municipais de Saúde organiza o processo, no que se refere aos instrumentos para efetivar o planejamento; $87,5 \%$ informam que os instrumentos utilizados são os dados epidemiológicos, socioeconômicos, demográficos e administrativos.

O sistema de informações produzido pelo SUS alimenta o trabalho desenvolvido pelas secretarias e tem fundamental importância no aprimoramento da gestão municipal. Assim, ao perguntar ao gestor se o Ministério da Saúde passa informações à Secretaria, 81,3\% respondem que sim. Percentual semelhante afirma que as secretarias utilizam as informações referentes à morbi-mortalidade, produção, Sistema Ambulatorial (SAI/SUS), Autorização de Internação Hospitalar (AIH) e dados do IBGE; para $31.3 \%$ dos gestores, o ministério oferece informações relativas à avaliação de serviços e cobertura; $6,3 \%$ deles recebem informações epidemiológicas, sobre vacinação, controle e avaliação, portarias e todas as informações do DATASUS. O fluxo das informações das SES para as SMS acontece para 50\% dos gestores, sendo que $12,5 \%$ deles afirmam receber informações relativas a residentes atendidos em outros municípios, e mais $12,5 \%$ são informados sobre estatísticas de saúde e produção de serviços. Paralelamente, $68,8 \%$ dos gestores consideram que as SES têm apoiado tecnicamente as SMS através de treinamento dos serviços (25\%), vigilância, controle e avaliação (18,8\%).

Contrariamente ao esperado, o apoio técnico à SMS por parte do Ministério da Saúde não tem acontecido para $62,5 \%$ dos entrevistados. Os programas de saúde direcionados e estimulados pelo ministério, para serem implantados nos municípios, com a finalidade de se acolherem nas normas regulatórias que definem o modelo de gestão municipal e os recursos financeiros específicos adequados a estes modelos, não apresentam consenso sobre sua relevância entre os gestores dos cinco municípios estudados. No caso do Programa de Atenção Básica, 43,8\% dos gestores não se manifestam a respeito, enquanto que os $46,2 \%$ restantes se distribuem de maneira quase equivalente entre considerações do tipo: "previne doenças e promove a saúde; tem carência de recursos, fortalece a base, trata-se de uma função do poder público, tem poder de resolutividade, está em discussão na secretaria”. A respeito do Programa de Saúde da Família, 18,8\% não se manifestam e $18,8 \%$ respondem que está sendo implementado com características diferentes conforme o município, 18,8\% ainda não o implementaram completamente e os restantes se distribuem através das seguintes considerações: "objetiva mudar o modelo assistencial e a maneira em que está sendo efetivado está causando impacto”. Por último, sobre o Programa de Agente Comunitário, igual ao item anterior, 18,8\% não se manifestam e os gestores restantes também fazem considerações similares às realizadas sobre o Programa de Saúde da Família.

A incorporação da comunidade/usuários, através dos Conselhos Municipais de Saúde, como modalidade de controle social constitui uma característica singular da política de saúde que atravessa o processo de implementação do SUS. Assim, a importância e o alcance dados ao papel dos Conselhos Municipais no processo decisório das SMS devem ser considerados como um aspecto singular do exercício de participação cidadã-comunitária. Desta forma, ao indagar, em primeiro lugar, sobre a participação do primeiro e do segundo escalão da SMS nas reuniões do Conselho, constatamos que 93,8\% dos gestores desses níveis participam das reuniões. A maioria dos gestores (75\%) afirma que os Conselhos se reúnem mensalmente. Os temas privilegiados nas reuniões têm sido para $57,6 \%$ dos entrevistados a política de saúde municipal, orçamento, leis de diretrizes e programas; $18,8 \%$ não se manifestam e os demais, com iguais $6,3 \%$ cada, se referem a: prestação de contas do Fundo Municipal de Saúde; convênios e consórcios; e usuários. Para 93,8\% dos entrevistados as reuniões são deliberativas e para $100 \%$ deles as discussões e propostas do Conselho influem nas decisões da SMS. As indagações realizadas nos permitem afirmar que os temas discutidos pelos Conselhos integram as agendas de governo local; a capacidade de os Conselhos influenciarem o processo decisório é dado por $75 \%$ dos entrevistados pelo caráter deliberativo e fiscalizador dos mesmos, enquanto para $18,8 \%$ deles é pela capacidade de inter- 
ferência que tem o movimento social nesses municípios. Os temas que aparecem mais freqüentemente como integrando a agenda política das secretarias têm sido: o regimento interno do CMS e a própria lei de criação dos Conselhos; a solicitação de credenciamento de serviços, problemas financeiros, recursos humanos e privatização e reformulação do organograma da SMS.

Os recursos municipais de saúde nessas localidades são depositados no Fundo Municipal de Saúde e geridos pela SMS, sendo que o papel do Conselho na gestão do fundo é o de fiscalizador para $68,8 \%$ dos entrevistados; de planejamento do orçamento municipal para $12,5 \%$; apenas $6,3 \%$ falam de parceria com a SMS; e $6,3 \%$ dos entrevistados referem-se, também, à existência de uma fundação que presta contas ao Conselho. Em quase todos estes municípios há também o Conselho Municipal de Assistência Social, mas as relações entre os dois órgãos ainda não são relevantes, $18,8 \%$ dos entrevistados expressam a existência de um representante do CMS no CMA e/ou vice-versa, $18,8 \%$ não se manifestam e o restante dos entrevistados consigna que não há relação ou que é incipiente.

A seguir será visto o envolvimento das SMS com os programas de saúde, sejam os programas definidos pelo MS ou pelas SES. Não importa a instância, estes programas são indicativos da vontade, de uma parte, de incrementar e racionalizar recursos financeiros das SMS e, de outra, de buscar uma maior eqüidade no acesso à saúde. Os programas privilegiados nos municípios estudados foram, em ordem de importância: a) o Programa de Saúde da Família (PSF), b) o Programa de Saúde da Mulher (PAISM), c) o Programa de Saúde Materno-Infantil (PSMI) e d) o Programa de Pré-Natal (PPN). Os critérios contemplados para o estabelecimento de prioridades nessas áreas sustentam-se para 56,3\% dos gestores nos incentivos financeiros do MS e pelos dados epidemiológicos/socioeconômicos; $25 \%$ dos entrevistados referem-se à intenção de reverter o modelo hospitalocêntrico na busca de um acesso à saúde de caráter preventivo e de educação em saúde. E 25\% manifestam que as discussões encaminhadas pelos Conselhos Municipais de Saúde tiveram um papel decisivo na definição dos programas nos cinco municípios estudados. Em relação à cobertura, 75\% dos gestores afirmam que $80 \%$ da população do município é coberta pelos programas e que na sua maioria os beneficiados são munícipes carentes, en- quanto $18,8 \%$ afirmam que os programas são direcionados a toda a população. No que se refere aos instrumentos de controle para o ingresso aos programas, a maioria dos gestores $(93,8 \%)$ informam que utilizam sistema de cadastros.

Os recursos orçamentários destinados aos programas são de caráter permanente (75\%), e as fontes de receitas se originam no SUS, mais do que nos recursos orçamentários do município, dado que, para $81,3 \%$ dos gestores, os programas contam com recursos externos, na sua maior parte oriundos do MS. As secretarias definem como prioridades para alocação de recursos: os dados epidemiológicos, as decisões tomadas pelo Colegiado de Gestão e, por último, as decisões da Conferência Municipal de Saúde ou da Secretaria de Orçamento Participativo nos municípios, onde esta última existe.

Os profissionais envolvidos nos programas são, na sua maioria, funcionários das SMS e contratados, escolhidos segundo especialidade médica, num número não inferior a 20 nem superior a 100, dependendo da dimensão do programa no município. No que se refere à remuneração dos profissionais, a maioria dos gestores $(56,3 \%)$ responde que a remuneração é adequada à carga horária; $12,5 \%$ respondem que a remuneração é adequada à carga horária e titulação, e percentagem similar responde que a remuneração é definida como gratificação em cargo de confiança.

Para 68,8\% dos entrevistados, a coordenação se exerce pela própria Coordenação de Programas da SMS; e para 12,5\%, ela se faz pelos Distritos Sanitários. Para 93,8\% dos gestores houve avaliação do programa: para 43,8\% houve avaliação de custo e produção; $18,8 \%$ não se pronunciaram; e segundo $12,5 \%$ foi feita avaliação sobre satisfação dos usuários. Os demais gestores se distribuem no sentido de dizer que houve avaliação de dados de morbi-mortalidade, reuniões entre supervisores e coordenadores e seminários de análise de dados e de impacto.

Dentre os gestores das SMS, 81,3\% declaram ter recebido manifestações e/ou informações dos usuários sobre os programas: $37,5 \%$ dos entrevistados afirmam ter recebido manifestações de apoio, 18,8\% dos usuários participaram nas Conferencias Municipais de Saúde e reuniões dos CMS e 12,5\% têm recebido solicitações dos usuários para alocação de programas. Em 81,3\% dos casos, o Conselho Municipal de Saúde (CMS) participou da formulação 
dos programas, e no que se refere ao tipo de participação dos CMS, 37,5\% respondem que esta tem acontecido em discussões e deliberações no CMS; $31,3 \%$ afirmam que o conselho participou aprovando programas e $12,5 \% \mathrm{fa}$ lam do papel do conselho na definição e formulação dos programas.

O acompanhamento dos programas para $25 \%$ dos gestores é feito pela supervisão e fiscalização do movimento social; para outros $25 \%$ é feito via reuniões sistemáticas e avaliação dos dados de morbi-mortalidade e para $18,8 \%$, pela coordenadoria de saúde coletiva. De maneira geral, em quase $100 \%$ dos casos, os programas respondem às demandas da população, demandas estas que foram detectadas através de indicadores de morbi-mortalidade (50\%), diagnóstico de cada comunidade (12,5\%), e as demais categorias alcançam apenas 6,3\% e são estatísticas acerca do trabalho nas unidades, estudos cadastrais dos programas, informações fornecidas pelos profissionais e pelas Conferências Municipais e CMS. Na maioria dos casos $(75,5 \%)$ houve diagnóstico prévio à formulação do programa.

Na opinião de $100 \%$ dos entrevistados os programas de saúde implementados no município tiveram sucesso, sendo que $37,5 \%$ afirmam que as evidências do sucesso são pelo fato de possibilitarem o controle de situações de risco para a saúde pública. As dificuldades na condução dos programas se localizam na disponibilidade de verbas e recursos humanos, de acordo com $56,3 \%$ dos entrevistados e $18,8 \%$ não se pronunciam a respeito. Para $75 \%$ dos gestores há problemas na implantação dos programas. Os empecilhos têm sido atribuídos à burocracia do serviço público, por $25 \%$ dos gestores; outros $25 \%$ não se manifestam; $18,8 \%$ atribuem as dificuldades encontradas à lentidão na compra de material, aprovação de projetos e pagamentos; $12,5 \%$ atribuem aos instrumentos de controle e $12,5 \%$ ao fato de que a troca cultural com a comunidade se dá de forma lenta. De qualquer maneira, $75 \%$ dos gestores manifestam não haver problemas de infra-estrutura nas SMS.

Para $100 \%$ dos gestores os programas são valorizados institucionalmente e isso se evidencia para $31,3 \%$ pela autonomia, apoio financeiro e pelo poder de decisão dado aos mesmos; para $18,8 \%$ pela estratégia de implementação de um novo modelo assistencial; para 31,3\%, por serem considerados como prioridade da política de saúde, no gerenciamento da mesma, e pelo primeiro e segundo escalões das SMS e para $18,8 \%$ os projetos das secretarias se identificam com os programas. Finalmente, $87,5 \%$ dos gestores consideram que os programas são prioridade do governo: do governo federal $(43,8 \%)$ e do governo municipal $(25,5 \%)$.

Cabe ressaltar que, de uma parte, os programas desenvolvidos pelas secretarias municipais e cuja origem está no Ministério da Saúde refletem aspectos relativos à racionalização de recursos financeiros. Ao liberar recursos próprios do município e incorporar recursos específicos, o ministério direciona o atendimento à prevenção, à educação, à detecção precoce de doenças e à atenção para populações com extremas carências. Assim facilita a captura de usuários que de outra maneira não teriam acesso ao SUS, gerando sua inclusão na política municipal.

Em relação ao Programa Comunidade Solidária, carro-chefe do governo na área assistencial a populações de baixa renda, $68,8 \%$ dos gestores informam que o mesmo não atua no município e $87,5 \%$ não se pronunciam em relação a algum tipo de envolvimento da SMS com o programa.

Por último, o estudo indagou sobre um conjunto de questões relativas à incorporação de inovações na gestão do sistema de saúde municipal. Para 93,8\% dos gestores, foram incorporadas inovações no decorrer da gestão. Interpelados sobre quais seriam, $31,3 \%$ informaram que gerências distritais e conselhos gestores de unidades foram criados como uma modalidade de gerência inovadora no município; $18,8 \%$ respondem que as inovações corresponderam a mudanças no modelo assistencial, enquanto $49,9 \%$ dos gestores se debruçaram sobre aspectos específicos da gestão municipal. Dentre eles: citam que inovações foram introduzidas na qualificação de gerentes, na autonomia financeira para alguns serviços, na utilização de verba da saúde em saneamento básico, na constituição de guardas sanitários, no programa de saúde da família, no atendimento à comunidade indígena e hemocentros, na melhora de relações com a rede conveniada, no programa de médicos de família, nas policlínicas comunitárias, na co-gestão, nos programas de vigilância à saúde. $\mathrm{E}$ ainda: $56,3 \%$ se referem à participação do município em Consórcios Intermunicipais de Saúde.

Em relação às inovações na gestão de recursos humanos em saúde no município, $87,5 \%$ respondem positivamente; indagados sobre o 
tipo de inovações incorporadas, 31,3\% informam que estas aconteceram no treinamento de gerentes e profissionais; $12,5 \%$, na descentralização na área administrativa e da informatização; $12,5 \%$, na incorporação do processo participativo na elaboração do plano de cargos e salários; $12,5 \%$, na avaliação de desempenho e $12,5 \%$, em gestão participativa/capacitação/ gratificações. Os demais gestores, num total de $(6,5 \%)$, falam sobre a criação de dupla jornada/terceirização de alguns serviços, e sobre cursos de administração hospitalar e cooperativas.

De fato, o que o SUS gerou foi uma arena política extensa no sentido de que esta não se limita à esfera ministerial, já que pela via da descentralização da política de saúde, o processo decisório passa a envolver instituições, políticas e atores sociais da esfera federal, estadual e municipal. Conseqüentemente, a presença de organizações setoriais e de representações político-partidárias torna complexo o policy-making no setor da saúde. Poderíamos afirmar que não se verifica, no caso, a existência de uma modalidade pluralista de intermediação de interesses já que não há a presença de grupos de interesse diferenciados e pouco estruturados exercendo pressão e se utilizando dos counterveilling powers (poderes contrabalançados) para influenciar as políticas (Labra, 1999). As representações setoriais têm um perfil mais corporativo e, conseqüentemente, uma modalidade de intermediação de interesses condizente com o caráter destas organizações e grupos de interesse. Ainda que não se trate de grupos bemestruturados e com uma representação monopólica setorial, possuem o reconhecimento do Estado, como interlocutores e parceiros válidos no processo decisório do setor da saúde.

A partir da análise dos questionários aplicados aos gestores do sistema, podemos afirmar que o SUS possibilitou o exercício de uma prática de intermediação de interesses mais próxima da "concertação" já que se pode concluir, sem temer equivocar-nos em demasia, que tem se alcançado um relativo consenso em torno do Sistema Único de Saúde. Estes atores o consideram adequado ao preenchimento das necessidades de saúde da população e de reorientação do sistema preexistente visando a melhores e mais amplos valores de cobertura e qualidade na assistência e na prevenção.

Nesse sentido, cabe uma reflexão mais detida em relação a conceitos, como representação e qualidade do policy-making no setor. Até que ponto poderíamos pensar na especificida- de das modalidades de resolução de conflitos entre instâncias institucionais criadas para articular níveis de governo, instâncias intergestoras de governo - tripartite, bipartite - e incidência na implementação da política de saúde da União, estados e municípios, organizações sociais, associações comunitárias, de usuários, sindicatos dos profissionais de saúde, técnicoburocracia do setor, secretarias e serviços de saúde.

Da maneira em que se deu o processo de formulação do SUS, com ampla participação da sociedade civil organizada (Gerschman, 1995), e com propostas próximas à definição de um Welfare State social-democrata, possibilitou alcançar um amplo consenso na sociedade que sustentou a sua implantação desde a aprovação constitucional, no fim da década de 1980, até os dias de hoje. No entanto, o percurso político-econômico da década de 1990, marcado pela onda neoliberal, significou para o SUS uma trajetória não-linear e, também, de um certo distanciamento na ação política, se considerarmos os princípios constitucionais, mas sem que isso signifique o abandono da proposta originária, em função da legitimidade alcançada na década precedente.

Ainda que durante a década não houvesse reformulações significativas do SUS, as Normas Operacionais Básicas que regulam o setor trouxeram algumas alterações relacionadas ao modelo de assistência à saúde. As mudanças mais importantes incorporadas ao sistema têm sido a definição de programas de atenção básica, como uma maneira de cobrir assistencialmente os setores de população mais desassistidos, ou de baixo acesso, que correspondem aos que vivem em altos níveis de pobreza e/ou borderline da pobreza absoluta.

De fato, isso gerou uma extensa polêmica no setor relacionada à efetivação de políticas focalizadas e serviços simplificados para a atenção de grupos populacionais extremamente pobres e a conseqüente exclusão das classes médias do sistema. Essas mudanças levariam à perda do caráter universal do sistema de saúde, ao desinvestimento em recursos humanos, em instalações, em equipamentos e em preservação do parque hospitalar do país, facilitando o crescimento das formas de seguro privado para as classes médias. Outros pensam o contrário, pois seriam políticas complementares que, em lugar de quebra da cobertura universal à saúde, seu desenho possibilitaria a complementariedade da atenção sem diminuir a qualidade, ba- 
sicamente adaptando a assistência sanitária ao risco de extensão de doenças para populações extremamente pobres. Dessa maneira, o conflito universalização/focalização permanece, mas é um divisor de águas latente entre instâncias governamentais do sistema e organizações da sociedade nos processos de deliberação da política de saúde.

De que maneira e sobre que questões o conflito se precipita? Quando indagados sobre a participação do Conselho Municipal de Saúde, os gestores, em quase todos os casos, respondem que o conselho participa na definição da política, e do controle de sua implementação e da fiscalização do Fundo Municipal (onde está depositado o orçamento municipal da saúde). Mas de fato, os mesmos gestores expressam que há pouca discussão nos conselhos sobre orçamento, prestação de contas do fundo, problemas dos usuários, diretrizes e programas. $\mathrm{Na}$ nossa compreensão, são essas as questões precipitadoras de conflitos no âmbito dos conselhos. Situação que se explica pela baixa vocalização de demandas da comunidade, o que os coloca numa posição mais frágil, tanto política, quanto tecnicamente.

Por um lado, a formação dos conselheiros não é suficiente para lhes permitir a tomada de decisões em assuntos de caráter técnico. Originariamente compostos por organismos comunitários, os Conselhos são mais um espaço de representação corporativa, onde organismos de representação de usuários portadores de doenças - deficientes físicos, portadores de HIV, renais crônicos etc. - atuam junto a representantes dos profissionais de saúde, do setor filantrópico e dos representantes dos órgãos governamentais. Isso conduz a que nas reuniões do conselho se discutam prioritariamente as questões levantadas pelos representantes da SMS, que em geral apresentam pacotes já definidos nas instâncias intergestoras - tripartite e bipartite - encaminhadas por sua vez pelo Ministério da Saúde. Esses programas passam pelo Conselho, onde os representantes disputam benefícios específicos, operando-se assim sua primeira adaptação ao contexto municipal.

Poderíamos afirmar que o policy-making resulta de uma modalidade de intermediação de interesses na qual as organizações da sociedade, sindicatos de profissionais e burocracia política agem de maneira a contornar o conflito. Como sugere Labra (1999), referindo-se às características salientes do processo decisório do setor da saúde: ...o modelo de policy-making tende a configurar-se em clusters de "redes políticas" ou de "comunidades políticas" cada vez mais especializadas e restritas, das quais participam apenas representantes da burocracia estatal qualificados legal e politicamente para tanto.

Cabe acrescentar que os conselhos têm um papel contraditório no processo decisório: dar andamento a uma política na qual as decisões aprovadas pelos mesmos não se originam nesse âmbito de representação da sociedade, mas em foros específicos das três instâncias governamentais sendo processadas nas Comissões Intergestores. Essa situação atualiza de maneira permanente o conflito latente dos pesos desiguais entre burocracias políticas, profissionais de saúde e organismos de representação da sociedade e usuários.

No caso das democracias industriais avançadas, diversos autores, como King (1988) e Esping-Andersen (1995), chamam a atenção para as dificuldades de desmonte do Welfare State. King observa que tais dificuldades se explicam pela incorporação da estrutura de benefícios dessas políticas às sociedades dotadas de uma longa tradição de luta. E que conseqüentemente possuem organizações sociais e políticas sólidas, capazes de enfrentar através da negociação/concertação os intentos de desmonte do Estado social. Esping-Andersen refere-se ao fato de que esses estados de bem-estar representaram além das preocupações limitadas à politica social... um mecanismo de integração social, de erradicação das diferenças de classe e de construção nacional e neste sentido parte da crise atual é devida a demandas menos tangíveis de novos modos de integração social, solidariedade e cidadania.

O pensamento desses autores desempenha o papel de nos fazer lembrar a distância entre a formulação da política de saúde, no momento político da transição para a democracia, sustentada sobre o direito universal à saúde e encaminhada a "saldar a dívida social" contraída pelo regime autoritário no Brasil (Gerschman, 1995), e o encaminhamento posterior que a jovem democracia brasileira deu a essas políticas, no fim da década.

$\mathrm{Na}$ conjuntura histórica do ajuste macroeconômico e no contexto latino-americano são visíveis os retrocessos nos processos de soberania nacional. Esses retrocessos são protagonizados por governos que chegam ao poder via partidos de cunho social-democrata, mas que implementam as políticas da "nova direita" ou como denomina Maier (1994) da retro-right. 
Em tais situações a representação política se desvanece e os direitos sociais universais se tornam um bem social difuso, ainda que sancionados constitucionalmente, como é o caso do Brasil.

No contexto de uma frágil experiência sociohistórica sustentada na mobilização e organização social política da sociedade, os conselhos locais de saúde, ainda que possuam uma existência legítima, carecem dos instrumentos políticos e técnicos capazes de transformar a lei em princípios executáveis para a viabilização de demandas sociais. Assim, no embate das forças políticas e dos grupos de interesse, o predomínio das burocracias técnico-políticas no processo decisório da política de saúde é notável.

\section{Os profissionais de saúde e o sistema local de saúde}

A segunda parte deste trabalho se localiza na ponta da linha do sistema de saúde municipal, qual seja os profissionais de saúde que lidam diretamente com a assistência à saúde dos usuários dos municípios estudados. De fato, explorar as inovações políticas incorporadas ao sistema municipal de saúde, junto à problemática do exercício da assistência direta aos pacientes, nos pareceu um bom contraponto para estabelecer, no futuro, parâmetros ou indicadores que permitam avaliar as políticas de saúde no âmbito local. 1

A análise dos profissionais de saúde será dividida em seis blocos temáticos.

\section{1) Perfil dos profissionais}

- Sexo

- Idade

- Tipo de profissional

- Tipo de serviço de pertenência

- Município de pertenência

\section{2) Grau de satisfação com o trabalho}

- Idade

- Sexo

- Tipo de profissional

- Tipo de serviço

- Município

\section{3) Infra-estrutura dos serviços}

- Tipo de profissional

- Tipo de serviço

- Município

4) Relações ou acesso a instâncias de governo - federal, estadual, municipal

- Tipo de profissional

- Tipo de serviço

- Município

\section{5) Suficiência de recursos humanos em saúde}

- Tipo de profissional

- Tipo de serviço

- Município

\section{6) Relação profissionais/usuários}

- Tipo de profissional

- Tipo de serviço

- Município

Dos profissionais de saúde entrevistados nos municípios selecionados, a maioria é composta de mulheres $(62 \%)$, com idade que varia de 36 a 45 anos (45,8\%). Destes, 75,5\% são médicos; 7,3\% são assistentes sociais; $6,8 \%$, enfermeiros e $3,6 \%$, dentistas, sendo que boa parte ganha entre 8 e 20 salários mínimos (50,0\%). A distribuição dos profissionais por tipo de serviço mostra que $65,2 \%$ trabalham em unidades ambulatoriais; $29,4 \%$, em hospitais, enquanto $5,4 \%$ trabalham em programas específicos.

Consideramos que o grau de satisfação dos profissionais de saúde expressa uma boa sinalização na avaliação do desempenho da atenção aos usuários. De fato, quanto menor a satisfação com o trabalho, maiores as probabilidades de desatenção e/ou falta de cuidados médicos com a comunidade. Mas o grau de satisfação, entendemos, deve ser avaliado diretamente associado à remuneração, às condições de trabalho, ao processo de trabalho e às outras variáveis consideradas a seguir, junto a uma avaliação indireta referida às condições de operacionalizacão dos serviços de saúde. Ou seja, buscamos observar os recursos humanos capazes de mobilizar os serviços, as atividades que signifiquem parâmetros mais humanizados nas relações médico-paciente, as modalidades de integração de cada um desses serviços de saúde ao sistema como um todo e qual o papel dos 
profissionais médicos na integração dos serviços. Consideramos importante a presença no exercício da profissão em saúde, de noções/ ações que expressem uma compreensão mais abrangente da assistência médica.

A análise dos dados evidencia que o grau de satisfação com as condições de trabalho é bom para a maioria dos entrevistados $(60,7 \%)$ e este percentual se mantém com pouca diferença entre homens $(59,7 \%)$ e mulheres $(61,3 \%)$. Já em relação à remuneração, a maioria $(50,8 \%)$ considera regular; enquanto $30,9 \%$ respondem que estão satisfeitos. As diferenças entre homens e mulheres são de pouca significância no grau de satisfação com a remuneração: 50\% dos homens e $51,3 \%$ das mulheres a consideram regular. A satisfação com o trabalho é mais pronunciada entre os profissionais até 35 anos, na faixa dos 40 e maior de 40 diminui o grau de satisfação. A mesma tendência se observa com a remuneração onde se nota uma ligeira acentuação de descontentes nas faixas etárias mais altas.

Em relação à carga horária, as mulheres estão mais insatisfeitas que os homens, já que $25,2 \%$ respondem que é regular - o que supõe sobrecarga. Somente 15\% dos homens a consideram regular. Dos que respondem que estão satisfeitos $80,0 \%$ são homens e $72,3 \%$ são mulheres. Com as oportunidades de aperfeiçoamento, $43,1 \%$ dos homens manifestam grau de satisfação regular e 26,4\%, ruim. Das mulheres, $31,3 \%$ acham ruim as oportunidades de aperfeiçoamento e 35,3\%, regular. Já o processo de trabalho é avaliado como bom por $70,8 \%$ dos homens e por $60,2 \%$ das mulheres. Para $38,1 \%$ das mulheres e $23,6 \%$ dos homens o grau de satisfação com o processo de trabalho é regular.

Dos jovens, $28,6 \%$ consideram a carga horária regular, fazendo pressupor sobrecarga de trabalho. Entre os profissionais de 36 a 45 anos, apenas $18,6 \%$ têm a mesma avaliação e o percentual é menor ainda $(15,8 \%)$ no grupo acima de 45 anos.

O descontentamento no trabalho, portanto, tende a ser mais alto nos jovens: 70,4\% acham regular e ruim as oportunidades de aperfeiçoamento e no que se refere ao processo de trabalho, $44,4 \%$ dos mais jovens o consideram regular e $54 \%$ o consideram bom. Observa-se uma aprovação mais acentuada com o processo de trabalho, entre os mais velhos.

A satisfação com as condições de trabalho é maior nas unidades ambulatoriais $(65,6 \%)$ do que nos hospitais $(55,6 \%)$ e programas $(50,0 \%)$.
Surpreendentemente em relação à remuneração, a satisfação é menor entre os profissionais que trabalham em unidades ambulatoriais $(27,9 \%)$ se comparados com os profissionais de hospitais (37\%) e de programas (40\%).

O grau de satisfação com a higiene dos estabelecimentos se distribui entre $72,7 \%$ que manifestam que é bom nas unidades ambulatoriais, $66,7 \%$ nos hospitais e $80,0 \%$ nos programas. A carga horária é bem-avaliada nas unidades ambulatoriais $(75,2 \%)$ e nos hospitais $(79,6 \%)$, mas existe sobrecarga no caso dos programas, nos quais $55,6 \%$ respondem que ela é apenas regular. No que se refere às oportunidades de aperfeiçoamento são melhores nos programas $(50,0 \%)$. O processo de trabalho é avaliado positivamente pelos profissionais de saúde, nas unidades ambulatoriais, $(68,9 \%)$ e nos programas $(66,7 \%)$ mais do que nos hospitais $(57,4 \%)$.

O estado de conservação das instalações dos serviços é considerado bom para 63,3\%, em Volta Redonda; 60,0\% em Niterói e Resende; 57,5\% em Angra dos Reis e 53,5\% em Duque de Caxias. Os aspectos indagados através dos profissionais de saúde com relação à infraestrutura em saúde dos municípios estudados mostram que, na variável estado de conservação aparelhos/equipamentos, o município que alcançou maior aprovação foi Volta Redonda com $60,0 \%$; os quatro restantes estão, com diferenças mínimas, em aproximadamente $50 \%$. A existência de medicamentos em quantidade suficiente é notavelmente desfavorável na maioria dos municípios estudados, sendo que em Niterói para 23,1\% dos profissionais a quantidade é suficiente, enquanto para 76,9\% é insuficiente. Dos restantes, Volta Redonda tem uma relação mais favorável relativa à suficiência $(46,7 \%)$, mas $53,3 \%$ dos profissionais respondem que é insuficiente. Os demais municípios registram percentagens em torno de $35 \%$ de suficiência e $65 \%$ de insuficiência. Indagada pelos motivos da insuficiência, a maioria responde que a reposição é irregular $(67,8 \%)$.

Neste item o estado de conservação das instalações é considerado melhor nos "programas", assim como a "conservação de aparelhos e equipamentos". A suficiência de medicamentos é mais alta em hospitais $(60,4 \%)$ do que em programas $(30,0 \%)$ e ambulatórios $(25,0 \%)$. Os motivos de insuficiência nos três tipos de serviços se relacionam com a reposição considerada insuficiente e/ou irregular por $66,7 \%$ dos profissionais que trabalham nas unidades 
ambulatoriais; por $85 \%$ dos profissionais que trabalham em hospitais e pela existência de procedimentos burocráticos por $42,9 \%$ dos profissionais dos programas. Essas mesmas variáveis analisadas por categorias profissionais evidenciam que os que mais reclamam do estado de conservação das instalações são os dentistas, assistentes sociais/psicólogos e médicos. Em relação a aparelhos/equipamentos os psicólogos e médicos são os que mais se queixam. E com a insuficiência de medicamentos, os dentistas, enfermeiros e assistentes sociais/psicólogos são os mais insatisfeitos.

A relação dos profissionais de saúde dos municípios com as instâncias executoras da política de saúde é escassa, varia de um município para outro e de outro lado, fora dos Conselhos Municipais, não há âmbitos institucionais de reunião e de comunicação regular.

No caso do município de Resende, para $60,5 \%$ dos profissionais deste município, os problemas da Unidade são discutidos com a SMS. Os problemas referem-se a atendimentos, recursos humanos, organização e infra-estrutura. Nos outros municípios, segundo aproximadamente $75 \%$ dos profissionais não há discussão dos problemas da unidade com as secretarias. No entanto, existe uma contradição nas falas, pois a maioria dos profissionais afirma que não há dificuldades para discutir problemas com as secretarias municipais.

No que se refere ao desempenho das SMS, os mais altos percentuais de apreciação de bom desempenho correspondem aos profissionais do município de Niterói $(73,0 \%)$ e Resende $(69,4 \%)$, ficando a seguir Duque de Caxias (65\%), Volta Redonda (59,3\%) e Angra dos Reis $(57,9 \%)$. Já na apreciação do desempenho do SUS, os valores são mais baixos, sendo que na maioria dos casos a resposta é que "deixa a desejar” para 60,7\%, em Niterói; e para 44,8\% em Duque de Caxias. Nos municípios de Angra dos Reis, Volta Redonda e Resende, 47\% dos profissionais, em média, respondem que o desempenho do SUS é bom e 30\% dizem que "deixa a desejar".

A percepção que os profissionais de saúde têm em relação aos recursos humanos dos serviços de saúde municipal possibilita compreender grande parte das dificuldades que atravessam os serviços no dia-a-dia da atenção à saúde. A sobrecarga de trabalho, a inadequação do número de profissionais às necessidades dos serviços, as causas de insuficiência de profissionais, as carências das especialidades de médicos, os motivos de insatisfação com o trabalho são algumas das variáveis que indagaremos a seguir.

A sobrecarga do trabalho profissional é mais notável nos "programas" (90\%) do que nos "hospitais" (50\%) e nas "unidades ambulatórias" $(48,4 \%)$. As causas da sobrecarga nas unidades e hospitais são atribuídas ao não preenchimento de vagas e ao mesmo tempo ao crescimento excessivo da demanda. Para a maioria dos profissionais nas unidades ambulatoriais, o número de profissionais é inadequado (65,5\%), enquanto as respostas relativas à "adequação/ inadequação" de profissionais em hospitais e programas se distribuem de maneira similar: $50 \%$ afirmam que o número é inadequado em ambos.

Para os profissionais das unidades ambulatoriais a carência de médicos se concentra em clínicos e especialistas; já no caso dos hospitais, faltam especialistas $(59,3 \%)$ e para $100 \%$ dos profissionais dos programas a carência principal é de médicos clínicos. A remuneração dos profissionais nos três tipos de serviços é considerada inadequada. A relação entre carga horária e remuneração seria adequada para a maioria dos profissionais de saúde se atingisse os seguintes valores:

a) para os profissionais de unidades ambulatoriais, quem trabalha até 20 horas deveria receber entre $\mathrm{R} \$ 800,00$ a $\mathrm{R} \$ 1.500,00$;

b) ainda para os profissionais de unidades ambulatoriais, a remuneração para quem trabalha entre 20 e 30 horas na semana deveria partir de um limite mínimo de $\mathrm{R} \$ 1.300,00$ até um máximo de $\mathrm{R} \$ 3.000,00$. Esta relação seria compartilhada também pelos profissionais que trabalham em hospitais;

c) para os profissionais dos programas, quem trabalha entre 30 e 40 horas deveria receber uma remuneração mínima de $\mathrm{R} \$ 3.000,00$ e máxima de $\mathrm{R} \$ 4.000,00$ e quem trabalha mais de 40 horas uma remuneração entre $\mathrm{R} \$ 5.000,00$ até $\mathrm{R} \$ 10.000,00$.

De um modo geral, a satisfação dos profissionais de saúde com o trabalho desenvolvido é de $90 \%$ para quem trabalha em programas; $82,6 \%$ para os profissionais das unidades ambulatoriais e $75,9 \%$ para os que trabalham nos hospitais do município. A maioria dos profissionais expressa a existência de problemas no exercício do trabalho $(56,0 \%)$, sendo que os mencionados com mais freqüência são os de infra-estrutura $(35,0 \%)$; de recursos humanos $(34,0 \%)$; e de excesso de demanda (14,6\%). 
A última das variáveis analisadas refere-se à relação dos profissionais de saúde com os pacientes, já que parâmetros de comportamento diferenciados na relação médico/paciente constituem uma evidência importante da compreensão da saúde-doença como um processo mais amplo que a exclusiva prescrição médica no momento da consulta. De fato, esses aspectos revelariam uma modalidade diferenciada de operacionalização do sistema que se torna realidade, na qualidade e densidade do contato do médico com o usuário. As questões indagadas correspondem ao tempo de consulta, à existência de relação com a clientela, ao tipo de relação fora da consulta, ao levantamento de informações sobre as condições de vida dos pacientes, ao tipo de informações colhidas e à utilização destas informações.

Nas unidades ambulatoriais, o tempo de consulta é, em média, 15 minutos para 27,3\% dos profissionais; para 33,3\% dos profissionais dos hospitais é de menos de 10 minutos e para $50 \%$ dos profissionais dos programas é, em média, de 30 minutos. A relação com a clientela existe para $70 \%$ dos profissionais dos programas, para $31,1 \%$ dos profissionais das unidades ambulatoriais e para 27,8\% dos profissionais dos hospitais. Quanto à modalidade de "relação com a clientela" a maioria informa que esta se dá através de "visitas domiciliares ou grupos". Levantamentos sobre condições de vida dos pacientes são coletados pela maioria dos profissionais $(81,6 \%)$; as informações levantadas por $56,0 \%$ deles se relacionam com o histórico familiar, o modo de vida, a afetividade e o lazer. Com relação ao aproveitamento das informações, a maioria dos profissionais expressa que são utilizadas para ajudar a definir a "conduta de tratamento".

\section{Conclusões}

Nas indagações relativas às inovações gerenciais e de recursos humanos, quase a totalidade dos gestores menciona sua incorporação no sistema municipal de saúde. O tipo de inovação se refere, na sua maioria, à criação de gerências distritais e conselhos gestores de unidades com participação da comunidade. Ocupam o segundo lugar as inovações no modelo assistencial. Na gestão dos recursos humanos, a maior parte considera que houve inovações no treinamento de gerentes e profissionais, na inclusão de processos participativos na elabora- ção do plano de cargos e salários, na descentralização da área administrativa e na informatização. Também, são mencionadas as inovações na avaliação de desempenho, na formação de cooperativas médicas, terceirização e na introdução de cursos de administração hospitalar. As inovações gerenciais aparecem refletidas, também, na incorporação de experiências das mais variadas, por exemplo, na implantação de políticas como a formação dos Consórcios $\mathrm{Mu}$ nicipais de Saúde; na implantação de programas, sendo alguns destes desenhados pelas Comissões Tripartites e Bipartites e outros de origem estritamente municipal: aumento dos orçamentos municipais para a saúde além do estipulado pela Constituição; incipientes iniciativas de intersetorialidade via programas de saúde municipais; e relacionamento das SMS com os Conselhos e na gestão dos recursos humanos.

De um modo geral, o que podemos afirmar é que as inovações estão acontecendo e resultam, por um lado, da intenção declarada pelos gestores municipais de efetivamente implementar o SUS, que no caso trata-se de uma técnico-burocracia do Estado, em quatro dos cinco municípios analisados, informada, e identificada no discurso com a proposta constitucional no setor da saúde, mas onde o lugar dos conselhos municipais no processo político foi catalisado pelos gestores municipais, tal como foi discutido acima. Por outro lado, a dimensão da flexibilização que acompanha a reforma do Estado nos aspectos de redimensionamento/encurtamento do mesmo e a redução de despesas na área social como parâmetro da gestão nos anos 90 atravessam também estas iniciativas.

Os dados expressam a abrangência de situações e processos relacionados às inovações na gestão da saúde municipal. Os resultados são extremamente diferenciados. Em alguns municípios, o tipo de inovação gerencial incorporada significa um claro avanço no processo de descentralização e implementação do SUS através de iniciativas da própria gestão municipal, indo além das diretrizes federais/estaduais, injetando recursos orçamentários próprios do município na implementação da política de saúde. Enquanto em outros, observa-se a implantação de programas e experiências formuladas exclusivamente no nível federal/estadual que são incorporadas pela gestão municipal como uma maneira de injetar recursos externos - principalmente do nível federal - no município. Aparecem também modalidades alternativas de gestão de recursos humanos, como 
no caso das cooperativas médicas no município de Duque de Caxias. Elas, que de fato, inovam nas relações de trabalho, mas descomprometem o governo municipal da responsabilidade histórica legitimada pelo Estado, da existência de relações trabalhistas sustentadas na estabilidade contratual e no pagamento de encargos sociais como aposentadoria, férias, décimo-terceiro e outros.

Os resultados alcançados em relação aos profissionais de saúde refletem a ausência de nitidez ou a presença de aspectos contraditórios que permeiam a política de saúde nas instâncias governamentais.

Os estudos referentes à satisfação no trabalho conseguem maior aprovação entre profissionais mais jovens. A mesma tendência se observa em relação à remuneração - os dados apresentam uma ligeira acentuação do descontentamento dos entrevistados nas faixas de idades mais altas. As oportunidades de aperfeiçoamento são melhor avaliadas nos programas; já no que se refere ao processo de trabalho este é melhor avaliado, pelos profissionais de saúde, nas unidades ambulatoriais e nos programas do que nos hospitais.

As mulheres estão mais insatisfeitas com a carga horária e com as oportunidades de aperfeiçoamento do que os homens. Essas diferenças se apresentam de maneira similar no julgamento do processo de trabalho como um todo.

A relação dos profissionais de saúde dos municípios com as instâncias executoras da política de saúde varia de um município para outro. Ainda que, em todos os municípios analisados, fora das reuniões regulares dos Conselhos Municipais, os profissionais dizem que não há instâncias institucionais criadas pelas secretarias municipais, nas quais participem com regularidade os profissionais dos serviços.

No que se refere aos recursos humanos existentes nos municípios, os profissionais de saúde das unidades ambulatoriais manifestam que há carência de médicos clínicos e especialistas; no caso dos hospitais, a carência se concentra em médicos especialistas e nos programas, a carência de médicos clínicos é mais acentuada. A remuneração dos profissionais nos três tipos de serviços é considerada inadequada. De um modo geral, a satisfação dos profissionais de saúde com o trabalho desenvolvido é alta para quem trabalha em programas, decrescendo, pela ordem, para os profissionais das unidades ambulatoriais e para os que trabalham nos hospitais. A maioria dos profissio- nais assinala a existência de problemas no exercício do trabalho, sendo os mais freqüentemente mencionados, em ordem decrescente, os problemas de infra-estrutura, de recursos humanos e de excesso de demanda.

O tempo de consulta nas unidades ambulatoriais é, em média, para a maioria dos profissionais, de 15 minutos; para os profissionais dos hospitais é de menos de 10 minutos e para os profissionais dos programas é de 30 minutos. A existência de "relação com a clientela" fora da consulta se dá através de "visitas domiciliares ou grupos”. Por último, as informações sobre as condições de vida dos pacientes, coletadas pela maioria dos profissionais, se relacionam com o histórico familiar, modo de vida, afetividade, lazer e são utilizadas basicamente para definir a conduta de tratamento de saúde.

Para a maioria dos médicos, o comprometimento com o SUS e o processo de descentralização está atrelado às condições de trabalho, oportunidades de formação, processo de trabalho e à remuneração alcançada no setor. Mas, pequena tem sido a preocupação das instâncias de governo local em criar mecanismos que incorporem os profissionais de saúde aos pressupostos de responsabilidade social e compromisso político no aperfeiçoamento dos serviços. Os médicos agem sob a pressão do exercício permanente de atenção aos pacientes e isso os libera de qualquer responsabilidade de outra natureza. Os gestores do sistema municipal agem sob a pressão política do governo municipal e, ainda que na sua maioria sejam profissionais médicos, esquecem que não há lugar para um sistema de saúde eficaz sem que seus elementos constitutivos, recursos humanos, equipamentos, infra-estrutura dos serviços e demandas sociais estejam permanentemente no centro das preocupações e do investimento do governo local. Esses fatores implicam, de fato, mudanças do policy-making no setor da saúde. 
Tabelas $^{\star}$

Tabela 1

Distribuição dos gestores do sistema municipal por sexo

\begin{tabular}{lrr}
\hline Sexo & N & \% \\
\hline Masculino & 4 & 25,0 \\
Feminino & 12 & 75,0 \\
Total & 16 & 100,0 \\
\hline
\end{tabular}

Tabela 2

Distribuição dos gestores do sistema municipal por critérios utilizados pela SMS para definir prioridades

\begin{tabular}{lcc}
\hline Critérios & N & \% \\
\hline Incentivo financeiro do MS, dados epidemiológicos e socioeconômicos & 9 & 56,3 \\
Reversão do modelo hospitalocêntrico & 4 & 25,0 \\
Regionalização das ações/o mesmo do SUS & 1 & 6,3 \\
Critério político e econômico & 1 & 6,3 \\
Mesmos critérios para o planejamento & 1 & 6,3 \\
\hline
\end{tabular}

Tabela 3

Distribuição dos gestores do sistema municipal por tipo de decisões sobre as quais a SMS tem autonomia

\begin{tabular}{lrc}
\hline Tipo de decisões & N & $\%$ \\
\hline Gestão da saúde & 8 & 50,0 \\
Gestão de recursos & 3 & 18,8 \\
Decisões técnico-operacionais & 5 & 31,3 \\
Total & 16 & 100,0 \\
\hline
\end{tabular}

Tabela 4

Distribuição dos gestores do sistema municipal por instâncias governamentais de formulação dos programas

\begin{tabular}{lrr}
\hline Instâncias governamentais & $\mathbf{N}$ & $\%$ \\
\hline Nível federal, adequados à realidade social & 10 & 62,5 \\
Em todas as instâncias & 1 & 6,3 \\
Fundação de saúde & 2 & 12,5 \\
Federal e estadual & 2 & 12,5 \\
Estadual & 1 & 6,3 \\
Total & 16 & 100,0 \\
\hline
\end{tabular}


Tabela 5

Distribuição dos profissionais por serviços, segundo os tipos de problemas no exercício do trabalho ${ }^{* *}$

\begin{tabular}{|c|c|c|c|c|c|c|c|c|}
\hline \multirow[t]{2}{*}{ Tipos de problemas } & \multicolumn{2}{|c|}{ Unid. Aten. Amb. } & \multicolumn{2}{|c|}{ Hospitais } & \multicolumn{2}{|c|}{ Programas } & \multicolumn{2}{|c|}{ Total } \\
\hline & $\mathrm{N}$ & $\%$ & $\mathrm{~N}$ & $\%$ & $\mathrm{~N}$ & $\%$ & $\mathrm{~N}$ & $\%$ \\
\hline Problema de infra-estrutura & 19 & 31,7 & 15 & 44,1 & 2 & 22,2 & 36 & 35,0 \\
\hline Problemas organizacionais & 9 & 15,0 & 2 & 5,9 & 1 & 11,1 & 12 & 11,7 \\
\hline Problemas com recursos humanos & 23 & 38,3 & 10 & 29,4 & 2 & 22,2 & 35 & 34,0 \\
\hline Falta de recursos financeiros & 2 & 3,3 & 1 & 2,9 & 1 & 11,1 & 4 & 3,9 \\
\hline Excesso de demanda & 7 & 11,7 & 5 & 14,7 & 3 & 33,3 & 15 & 14,6 \\
\hline Desmistificação do papel social do louco & 0 & 0,0 & 1 & 2,9 & 0 & 0,0 & 1 & 1,0 \\
\hline Total & 60 & 100,0 & 34 & 100,0 & 9 & 100,0 & 103 & 100,0 \\
\hline
\end{tabular}

** 89 profissionais responderam não ter problemas no exercício do trabalho

Tabela 6

Distribuição dos profissionais de saúde por município, segundo sobrecarga de trabalho do profissional

\begin{tabular}{|c|c|c|c|c|c|c|c|c|c|c|c|c|}
\hline \multirow{2}{*}{$\begin{array}{l}\text { Sobrecarga } \\
\text { de trabalho }\end{array}$} & \multicolumn{2}{|c|}{ Niterói } & \multicolumn{2}{|c|}{ Duque de Caxias } & \multicolumn{2}{|c|}{ Angra dos Reis } & \multicolumn{2}{|c|}{ Volta Redonda } & \multicolumn{2}{|c|}{ Resende } & \multicolumn{2}{|c|}{ Total } \\
\hline & $\mathrm{N}$ & $\%$ & $\mathrm{~N}$ & $\%$ & $\mathrm{~N}$ & $\%$ & $\mathrm{~N}$ & $\%$ & $\mathrm{~N}$ & $\%$ & $\mathrm{~N}$ & $\%$ \\
\hline Sim & 23 & 57,5 & 23 & 52,3 & 22 & 55,0 & 14 & 46,7 & 15 & 39,5 & 97 & 50,5 \\
\hline Não & 17 & 42,5 & 21 & 47,7 & 18 & 45,0 & 16 & 53,3 & 23 & 60,5 & 95 & 49,5 \\
\hline Total & 40 & 100,0 & 44 & 100,0 & 40 & 100,0 & 30 & 100,0 & 38 & 100,0 & 192 & 100,0 \\
\hline
\end{tabular}

Tabela 7

Distribuição dos profissionais de saúde por município, segundo carência de médicos ${ }^{\star \star *}$

\begin{tabular}{|c|c|c|c|c|c|c|c|c|c|c|c|c|}
\hline \multirow[t]{2}{*}{ Carência de médicos } & \multicolumn{2}{|c|}{ Niterói } & \multicolumn{2}{|c|}{ Duque de Caxias } & \multicolumn{2}{|c|}{ Angra dos Reis } & \multicolumn{2}{|c|}{ Volta Redonda } & \multicolumn{2}{|c|}{ Resende } & \multicolumn{2}{|c|}{ Total } \\
\hline & $\mathrm{N}$ & $\%$ & $\mathrm{~N}$ & $\%$ & $\mathrm{~N}$ & $\%$ & $\mathrm{~N}$ & $\%$ & $\mathrm{~N}$ & $\%$ & $\mathrm{~N}$ & $\%$ \\
\hline Clínicos & 13 & 54,2 & 5 & 17,9 & 1 & 3,6 & 5 & 31,3 & 2 & 9,5 & 26 & 22,2 \\
\hline Especialistas & 5 & 20,8 & 15 & 53,6 & 8 & 28,6 & 5 & 31,3 & 13 & 61,9 & 46 & 39,3 \\
\hline Clínicos e especialistas & 6 & 25,0 & 8 & 28,6 & 19 & 67,9 & 6 & 37,5 & 6 & 28,6 & 45 & 38,5 \\
\hline Total & 24 & 100,0 & 28 & 100,0 & 28 & 100,0 & 16 & 100,0 & 21 & 100,0 & 117 & 100,0 \\
\hline
\end{tabular}

*** 75 profissionais responderam não haver carência de médicos

\footnotetext{
* As tabelas inseridas no final do texto se justificam, apenas, como amostra do material da pesquisa analisado neste artigo.

O motivo pelo qual não foram incorporadas todas as tabelas analisadas se deve à limitação editorial da revista.
} 


\section{Nota}

${ }^{1}$ Ainda que este trabalho constitua o pontapé inicial, não será este o momento de elaborar os indicadores, já que os mesmos, pela própria metodologia que estamos propondo, necessariamente serão obtidos a partir dos resultados numéricos finais do conjunto dos questionários aplicados, após a análise dos mesmos e como produto final da pesquisa em questão.

\section{Referências bibliográficas}

Esping-Andersen G 1995. O futuro do welfare state na nova ordem mundial. Lua Nova. Revista de Cultura e Política no 35, Cedec.

Gerschman S 1995. A democracia inconclusa. Um estudo da reforma sanitária brasileira. Fiocruz, Rio de Janeiro.

Gerschman S 2000. A descentralização da política de saúde no final dos anos 90. Revista de Administração Pública 34(4), jul./ago., FGV.

King D 1988. O Estado e as estruturas sociais de bem-estar em democracias industriais avançadas. Novos Estudos no 22, out., Cebrap.

Kugelmas E \& Sola L 2000. Recentralização/descentralização dinâmica do regime federativo no Brasil dos anos 90. Tempo Social, fev., USP.

Labra ME 1999. Análise de políticas, modos de policy-making e intermediação de interesses. Uma revisão. Ensp/ Fiocruz, Rio de Janeiro, (mimeo).

Lobo T 1998. Descentralização uma alternativa de mudança. Revista de Administração Pública. 32(5), set./ out., FGV.

Maier Ch. 1994. Democracy and its descontents. Foreign Affairs, jul./aug.

Sallum B Jr 1996. Federação, autoritarismo e democratização. Tempo Social 8(2), out., USP.

Sallum B Jr 2000. O Brasil sob Cardoso neoliberalismo e desenvolvimento. Tempo Social fev., USP. 